\title{
Polymorphic Ventricular Tachycardia by ECG Finding
}

National Cancer Institute

\section{Source}

National Cancer Institute. Polymorphic Ventricular Tachycardia by ECG Finding. NCI

Thesaurus. Code C62236.

An electrocardiographic finding of a ventricular tachycardia in which the QRS complexes have a variable morphology and often rate. (CDISC) 